\title{
Mental Health Care in Saudi Arabia: Past, Present and Future
}

\author{
Harold G. Koenig1,2*, Faten Al Zaben², Mohammad Gamal Sehlo²,3, \\ Doaa Ahmed Khalifa ${ }^{2,4}$, Mahmoud Shaheen Al Ahwal'2, \\ Naseem Akhtar Qureshi5 ${ }^{5}$ Abdulhameed Abdullah Al-Habeeb ${ }^{5}$ \\ ${ }^{1}$ Duke University Medical Center, Durham, USA \\ ${ }^{2}$ King Abdulaziz University, Jeddah, KSA \\ ${ }^{3}$ Zagazig University, Zagazig, Egypt \\ ${ }^{4}$ Ain Shams University, Cairo, Egypt \\ ${ }^{5}$ Ministry of Health, Riyadh, KSA \\ Email: ${ }^{*}$ Harold.Koenig@duke.edu
}

Received 28 February 2014; revised 22 March 2014; accepted 29 March 2014

Copyright (C) 2014 by authors and Scientific Research Publishing Inc.

This work is licensed under the Creative Commons Attribution International License (CC BY).

http://creativecommons.org/licenses/by/4.0/

c) (i) Open Access

\begin{abstract}
We review the past, present and future state of mental health care in the Kingdom of Saudi Arabia (KSA). The past is reviewed prior to the modern era, discussing early explanations and treatments for mental health illness up through the establishment of the first mental hospital in the 1950s, tracking advances in mental health care over the past 60 years. The present is explored in terms of the current need for mental health care based on the prevalence of mental health problems in KSA. We also discuss the role of the family in caring for the needs of the mentally ill today. Finally, we look forward into the future, discuss the current education system that will produce the next generation of mental health professionals, examine areas of mental health care that need improvement, and provide a research agenda to guide the continued development of the mental health care system in KSA. Our goal is to present a blue print for the development of a state-of-the-art mental health that may serve as a model for other countries in the Middle East, while taking into account the political, cultural and religious factors that are unique to this region of the world.
\end{abstract}

\section{Keywords}

Mental Health Care, Saudi Arabia, Mental Health System, Psychiatry, Psychiatric Education, Middle East, Research

\footnotetext{
${ }^{*}$ Corresponding author.
} 


\section{Introduction}

The story of the development of mental health care in the Kingdom of Saudi Arabia (KSA) is one that other countries in the Middle East and all over the world can learn from as they transform their mental healthcare systems into state-of-the-art systems adapted to the challenges of the 21st century. Here we discuss how a modern mental health care system has emerged out of the historical past, what a modern mental healthcare system in a conservative Muslim country looks like today, and describe the steps needed to meet the challenges that KSA will face as it continues to improve and expand its mental health care system. This article builds on our previous work describing the evolving mental health system in this religiously conservative Middle Eastern country [1] [2].

\section{The Past}

Up until the early 1950's, there were no psychiatric hospitals anywhere in KSA, a country formed from nomadic tribal societies, a modern state that was barely 20 years old. ${ }^{2}$ Progress began with the building in 1952 of the Taif Mental Hospital in Shahar, an hour's drive southeast from Mecca, the cradle of Islam. By the early 1980's, however, there were still only two psychiatric hospitals to serve the Kingdom's population of 6 to 8 million.

Psychiatric research was also strikingly underdeveloped. In the early 1980's, the medical school at King Abdulaziz University in Jeddah had just begun to study biomedical aspects of the hajj, an event where more than 2 million visitors come to Mecca during the 12th month of the Islamic calendar (Dhu al-Hijjah). No research, however, was being done on how this massive pilgrimage affected the mental health of either the visitors or the residents of KSA. Almost no research existed on psychiatry and legal or ethical issues in KSA, in particular systematic information on the prevalence of human rights abuses by hospitals and mental health professionals, issues related to the patient's right to treatment, the insanity defense in criminal cases, and the patient's right to refuse treatment.

Commenting on the state of psychiatry in KSA in 1983, Pasnau and Hartmann recommended that U.S.-trained psychiatrists be recruited to improve "the quality of psychiatric treatment and in developing standards for a modern psychiatric hospital environment, outpatient care, psychotherapy, biopsychosocial approaches, and a mental health system adapted to Saudi culture" (p. 1493) [3]. These authors concluded that, "American psychiatrists may have an important role to play in the future of psychiatry in Saudi Arabia" (p. 1493). It is not known to what extent (if at all) American psychiatrists have contributed anything to the advances in psychiatric care seen in KSA during the past 60 years.

American psychiatrist, Steven Dubovsky, has emphasized the important role that Islam and pre-Islamic Saudi culture has played in the seeking of psychiatric care in KSA and in compliance with that care [4]. He referred to the widespread belief in in'shallah, the conviction that whether someone becomes sick or recovers is based on God's will, and that nothing can be done to change the course of illness. The result, according to Dubovsky, was "a passivity that mimics helplessness and makes achieving a therapeutic alliance in which the patient is actively involved in his or her own care extremely difficult" (p. 1456). We would rephrase and say that the result is a health belief system deeply grounded in religion and culture, which needs to be taken into account when examining and treating patients and planning mental health services. This important cultural perspective has traditionally been ignored by American psychiatrists in their own country. Hopefully, the introduction of DSM-V will help change this neglected dimension related to mental health [5].

Up through the early 1980's and to some degree still now, the treatment of those with mental illness-especially those with chronic psychotic disorders in rural areas-involved religious faith healing. This included treatments to exorcise demons or to counter the evil eye, jealousy, and magical forces thought to be responsible for the illness. Physical thrashings or cautery were used to get evil spirits to leave the body [6]. In those days, cautery was a common intervention that traditional healers used to treat many diseases, not just mental illness. An iron rod held by a wooden handle would be heated until the end glowed red and then applied to various body parts that were thought to be involved in the illness, especially the skull in psychotic disorders. Topical herbs might be applied after cauterization but no anesthesia or other medication was given. Not surprising, infection was a common complication. In contrast, the treatment of mental illness in large urban areas in the 1980's was more likely to involve medication and psychotherapy, although no particular model of psychotherapy was used, at least no Western model of psychotherapy was dominant.

Although not citing any research, Dubovsky in 1983 maintained that psychiatric disorders in women appeared 
to be increasing (possibly due to role conflicts arising from exposure to Western lifestyle and cultural ways). He admitted, though, that women might be more willing than men to seek psychiatric services, making it only appear that mental disorders were more common in this gender. Spouse abuse as well as child maltreatment were not considered crimes in the early 1980s, so no efforts at intervention were made to address these problems. In the end, Dubovsky suggested that the usual Western methods of identifying and treating psychiatric disorders would need considerable modification to be effective in this country.

Legal issues also influenced the way that psychiatry was practiced. If a psychotic patient was released from the hospital too early and assaulted someone, the psychiatrist himself might go to jail right along with the patient. As a result, psychiatrists began to practice defensive psychiatry and therefore were reluctant to release patients, resulting in long hospital stays. Psychiatric hospitals, however, were few in number and were usually over filled with long-term chronic patients. In 1983 there were only two hospitals dedicated to the treatment of mental illness, the Taif Mental Health Hospital in Shahar and a smaller one in Medina, although psychiatric wards in general hospitals were beginning to appear. Anti-psychotic drugs were commonly used at that time, although psychotherapy was seldom done with the chronic mentally ill who were usually medicated and housed.

Besides a small psychiatric residency at King Saud University, specialty training in psychiatry was also almost non-existent. A second psychiatry training program existed at the Taif Mental Health Hospital in Shahar that offered a diploma in psychological medicine. According to Dubovsky, this diploma would not fulfill residency requirements for certification. Other than a few lectures on depression and organic brain syndrome, or a week-long clinical clerkship working with a psychiatrist in one of the two mental hospitals, exposure to psychotherapy or psychopharmacology was infrequent in medical school.

No electroconvulsive therapy (ECT) was performed in KSA in the mid-1980s. Although first generation anti-psychotics including long-acting agents were used, they were often given at subtherapeutic levels since there were no guidelines for drug use in this part of the world. Likewise, lithium for bipolar disorder or for augmentation of depression treatment was not used. Both inpatients and outpatients tended to have antipsychotic-induced extrapyramidal symptoms that were often ignored by treating psychiatrists. One reason for this was that in the Arab world at this time, those who ran the mental health facilities were not well trained in psychiatry. Problems with substance abuse were often hidden and did not start receiving significant attention until the late 1990's.

\section{The Present}

Much indeed has changed over the last few decades. We first describe the prevalence of mental health problems in KSA today as an indicator of the present need for mental health services development and reform. We then discuss how the mental health system now operates in KSA and the availability of services and providers, comparing these with services in the United States and other developed countries around the world.

In order to determine the present need for mental health services in KSA and also to address whether or not the current mental health system is equipped to meet that need, information on the prevalence of emotional symptoms and emotional disorders in the population is of critical importance. Unfortunately, the only information that exists comes from regional studies or studies of special populations, which we now review.

With regard to the prevalence of mental disorders in the community overall, no information is available. However, a new study fielded in early 2013 may fill this knowledge gap (see below). The only systematic data based on a national sample comes from a study of Saudi's age 60 or over, although no data were collected on older expatriates [7]. Al-Shammari and Al-Subaie assessed depressive symptoms using the 30-item Geriatric Depression Scale (GDS) in 7,970 persons. Participants were identified using a two-stage process: first, a random sample of primary health care (PHC) centers throughout KSA was identified, and then a random sample of health records at each PHC center was determined to identify 8,000 families with older adults. Those persons were then interviewed in their homes, with a $99 \%$ response rate for males and $80 \%$ response rate for females. Results indicated that $31 \%$ scored 10 to 20 and another $8 \%$ scored 21 or higher on the GDS. A score of 10 or higher on the GDS indicates significant depression and 21 or higher indicates severe depression. Thus, 39\% reported signficant depressive symptoms, which tended to be more common in women (49\%) compared to men (33\%), those in remote or rural areas (45\%), the divorced or widowed (51\%), the illiterate (43\%), those not working (45\%), and persons over age 80 (52\%). Depression was also strongly related to number of medical diagnoses especially complaints of headache or joint pain, number of medications taken, and physical disability. Among elders who were dependent on others to help them perform their activities of daily living, $68 \%$ had sig- 
nificant depressive symptoms.

Regional studies of young persons have also reported relatively high rates of emotional symptoms. For example, Abdel-Fattah and Asal identified a systematic sample of 490 secondary school students in Taif, assessing depressive symptoms using the 21-item Beck Depression Inventory (BDI) [8]. Average age was 17 years and 38\% were female. One-third (33\%) scored 19 or over on the BDI (moderate to severe depression) and 11\% scored in the severe to very severe depression range. In multivariate analyses, females were about one-third more likely than males to score 19 or higher (40\% vs. 29\%). Birth order (last child), family history of chronic physical disease, and history of loss of a close relative were other predictors of depression.

In a second study of Saudi youth, Gelban examined psychiatric symptoms in high school students ages 14 to 19, reporting results on boys and girls in separate papers. In the first report on males [9], the 42-item Depression, Anxiety and Stress Scale (DASS) was used to assess symptoms in 1123 students attending all-boys schools in Abha. Fifty-nine percent had significant levels of either depression, anxiety or stress; $41 \%$ had significant levels of two or more of these symptoms; and 23\% had significant levels of all three symptoms. Overall, $36 \%$ reported stress, 38\% depression, and 49\% anxiety. In the second report that focused on females and used a different methodology [10], the Symptom Checklist 90 (SCL-90-R) was administered to 545 students at 10 all-girls schools in Abha. The most frequent symptoms were phobic anxiety (16\%), psychoticism (15\%), anxiety (14\%), somatization (14\%), and depression (14\%). Overall, 16\% had one or more type of symptom, $9 \%$ had two or more symptoms, $6 \%$ had three symptoms, and 4\% had all four symptoms. Greater psychiatric symptoms in males compared to females (the reverse of what is usually found) may have been due to differences in instruments used to assess psychiatric symptoms.

Thus, based on these three reports on secondary school students, between $16 \%$ and $59 \%$ have significant levels of mental or emotional symptoms. Interestingly, the prevalence of these symptoms in youth is not much different than found among adolescents in the U.S. For example, the Composite International Diagnostic Interview (CIDI) was administered to a national random sample of 10,123 adolescents ages 13 to 18 in the U.S. [11]. Anxiety disorders were present in 32\%, behavioral disorders in 19\%, mood disorders in 14\%, and substance abuse disorders in 11\%. Overall, 30\% had at least one class of mental disorder, and 22\% had disorders with severe impairment and/or distress.

A number of studies have also examined emotional symptoms in medical or primary care settings. For example, researchers administered the Patient Health Questionnaire (PHQ) to a consecutive sample of 431 medical outpatients seen at PHC centers in Riyadh [12]. Three quarters of participants were under age 50 and about half were female. The PHQ assesses symptoms of depression, anxiety, and somatization. Results indicated that $19 \%$ fufilled criteria for somatization, $20 \%$ for depression, $14 \%$ for generalized anxiety disorder, and 10\% for panic disorder. Overall, 33\% met criteria for at least one disorder. In females, rates were higher for somatoform disorder (13\% vs. $6 \%$ in males), depression (13\% vs. $6 \%$ ), and generalized anxiety disorder (9\% vs. $4 \%$ ).

Another primary care study involved a systematic random sample of 609 outpatients, with an average age of 34 and half female, who attended a PHC clinic at the Armed Forces Hospital in Al-Kharj [13]. The Rahim Anxiety-Depression scale was used to assess symptoms. The prevalence of "minor mental illness" was reported to be $18 \%$ and of subthreshold illness was $12 \%$, with $30 \%$ having one or the other. Mental illness was most prevalent among women (22\% vs. $14 \%$ in men) and in those with bronchial asthma (28\%). Finally, in a survey of 1042 outpatients seen at PHC centers in Riyadh, of whom 90\% were under age 50 and 57\% were female, 39\% scored 5 or higher on the General Health Questionnaire indicating emotional distress [14]. Based on these studies, clinically relevant emotional symptoms are present in 30\% - 39\% of medical outpatients seen in PHC centers, the majority of whom go undiagnosed and untreated.

High rates of undiagnosed, untreated mental illness in KSA primary care settings, however, is again not much different than the situation in the U.S. For example, in a multi-site study of 5053 U.S. primary care patients screened using the Patient Health Questionnaire, significant depressive symptoms ranged from 15\% in Chinese Americans to 22\% in Caucasian Americans [15]. Not examined, however, were anxiety, somatization, or other psychiatric symptoms. In a study of 1007 primary care outpatients in New York City, researchers used the PRIME-MD Patient Health Questionnaire to screen for psychiatric disorders. One in five patients (19\%) had major depression and nearly one in three (30\%) had a mental disorder of some kind [16]. Fewer than one-half had received any treatment in the past month.

Although no studies to date have examined the prevalence of mental disorders in the general Saudi community, there are now plans to conduct such a survey. The Saudi National Mental Health Survey (SNMHS) involves 
a collaboration between King Faisal Specialist Hospital and Research Center (KFSH \& RC), Prince Salman Center for Disability Research, the Ministry of Health, King Saud University, Harvard University, University of Michigan, Ministry of Economy and Planning, and King Abdulaziz City for Science and Technology (KACST). The study is being funded by grants from Abraj Capital, Sabic, King Saud University, KACST, and the Ministry of Health. A national random sample of 10,000 Saudi nationals, made up of 6500 from the community and another 3500 from primary health care centers, will be surveyed using the Composite International Diagnostic Interview (CIDI), a structured interview capable of making psychiatric diagnoses. The goal is to determine the prevalence, risk factors, comorbidities, treatment services, and outcome of mental disorders in KSA [17]. The CIDI is the same measure that was used to determine the prevalence of psychiatric disorders in the U.S. National Comorbidity Study [18] and has been used in more than 30 low- and middle-income countries worldwide [19].

Not only will the SNMHS interview include the CIDI, but also three additional sections on acute psychosis, the cultural dimension of psychiatric disorder, and dementia. The interview has been translated into Arabic by trained professionals, including psychologists under the direction of two consultant psychiatrists, and has been back translated to ensure accuracy and reliability. The Arabic version of the CIDI has now been validated using the Structured Clinical Interview for DSM-IV (SCID). More than 250 interviewers from all over KSA have been trained to administer the survey and the entire questionnaire has been computerized. The SNMHS is being conducted between 2013 and 2015, with data analysis and initial publications beginning in 2015. The planning phase of this survey started in early 2009.

While there is little information on mental disorders in the general Saudi population at the present time, research is available on the types of disorders and characteristics of treated patients seen in psychiatric specialty hospitals and psychiatric wards of general hospitals. We now briefly review that research here. In one of the first studies, researchers examined characteristics of patients admitted in the early 1990's to the Buraidah Psychiatric Hospital located in the Al-Qaseem region of KSA [20]. Of the 195 patients assessed, the majority were young males and 57\% had schizophrenia. These patients tended to have multiple admissions, high relapse rate, family history of mental illness, poor drug compliance, and stressors that precipitated hospital admission. The primary treatment was first generation antipsychotic drugs and anti-cholinergics. Over one-third of patients (38\%) had co-morbid medical illnesses treated during the hospital stay.

The characteristics of patients admitted to hospitals specialized in addictions treatment have also been examined. One of the first studies in the early 1990s assessed 116 consecutive inpatients admitted to the AlAmal Hospital in Dammam [21]. Most patients were young (83\% ages 21 to 32 years), all were male, and 97\% were Saudi nationals. Among the substances used, $49 \%$ injected heroin alone, $35 \%$ used heroin in combination with other drugs or alcohol, $11 \%$ used only alcohol, and an additional $20 \%$ used alcohol in combination with other drugs. Cannabis (marijuana) and stimulants were combined with other drugs by $26 \%$ and $10 \%$ of participants, respectively. Heroin users were more likely to be unemployed compared to alcoholics ( $54 \%$ vs. $31 \%$ ), and the duration of drug use was much longer in Heroin addicts.

A more recent survey of 736 male outpatients and inpatients at substance abuse hospitals in Riyadh, Dammam, and Jeddah updates these findings [22]. In that study, 98\% were current cigarette smokers, $40 \%$ used amphetamines, $20 \%$ alcohol, $17 \%$ heroin, $16 \%$ marijuana, and 3\% cocaine or volatile substances. Nearly all (99\%) had used these substances for 6 months or longer. The most prevalent co-morbid other mental disorders were depression (57\%) and anxiety (17\%). One in ten (11\%) also had either diabetes, hypertension, or other physical disorder. Most were Saudi nationals, two-thirds were unemployed, and over $25 \%$ were illiterate. To our knowledge, no more recent reports exist on the characteristics of patients in psychiatric hospitals or addiction treatment centers in KSA.

In contrast to patients admitted to specialty psychiatric hospitals, those admitted to psychiatric services of general medical hospitals display a broader range of diagnoses. AbuMadini and Rahim (2002) described the characteristics of 1,366 patients admitted to the psychiatric service of King Fahd Hospital in Al-Khobar between 1988 and 1998 [23]. Only 20\% had schizophrenia, the majority of whom were male, whereas $15 \%$ had bipolar disorder and $10 \%$ major depressive disorder, the majority of whom were female. Most of the remaining patients had acute psychoses, adjustment disorders, or dissociative disorders. Average length of stay was 25 days, and bed occupancy rate during the 10-year period was $85 \%$. Expatriates were more likely than Saudi nationals to be admitted with acute or transient psychosis, stress-related, or dissociative disorders.

The research reviewed above gives a sense of the prevalence and types of psychiatric disorders seen in KSA 
and underscores the current need for adequate mental health services.

\section{Advances in Mental Health Care}

Changes in KSA's mental health care system have been dramatic over the past 30 years. ${ }^{1,2}$ In 1989, KSA established primary health care (PHC) centers throughout the country in order to improve the diagnosis and treatment of medical problems in the community. All Saudis now receive their medical care in these centers. In order to improve the detection and treatment of mental health problems, the World Health Organization in 2000 encouraged countries to make PHC centers the point of first contact for those with mental disorders [24]. In situations where PHC physicians cannot handle these patients, the recommendation was to refer to psychiatrists in general hospitals (secondary level), and if psychiatrists in those settings couldn't manage patients, then they were to refer to specialty psychiatric hospitals or to teaching hospitals (tertiary level) [25]. Since most individuals first see their medical doctor for health problems, and psychiatric and medical illness often co-exist, the WHO viewed this system as the best way to identify and treat those with mental health problems. In KSA, which has followed the WHO recommendation, this process has worked reasonably well covering the majority of the population with mental health needs.

Patients in KSA can also go directly without referral to see psychiatrists at specialty psychiatric hospitals, and some patients seek help through emergency services at either general hospitals or psychiatric hospitals without a referral. Finally, there is a private mental health care system in KSA, where patients are seen for a fee, unlike the public system which is government-funded. In addition to free-standing private psychiatric clinics, there are over 125 private general hospitals, many with private psychiatric clinics connected to them [26]. Because of the stigma of mental illness and the ease of access to services, those who have the financial resources often prefer to consult private clinics and pay out of pocket. Private clinics offer psychotherapy, psychotropic drugs, addiction services, speech therapy, and rehabilitation services to children, adolescents, adults, and older adults.

Soon after KSA adopted the WHO recommended system of primary (PHC), secondary, and tertiary referral, Saudi researchers began to examine referral sources and characteristics of patients admitted to specialty psychiatric hospitals. One such study found that three-quarters of referrals to the Buraidah Mental Health Hospital came from PHC centers and the rest from general medical hospitals [27]. Referrals from general hospitals (vs. PHC centers) were more likely to be for psychotic disorders (20\% vs. $10 \%$ ), mood disorders ( $28 \%$ vs. $23 \%$ ), and psychosomatic disorders (7\% vs. 2\%), whereas referrals from PHC centers (vs. general hospitals) were more likely for somatic symptoms (35\% vs. $23 \%$ ) and neurological symptoms (8\% vs. $4 \%$ ).

Mental health services have continued to expand over time in KSA. By 2006, the country had developed a national mental health policy and established specialty programs for those with addictions, children and adolescents, the elderly, and consultation-liaison services in general medical settings. One of the biggest advances came with the 2007 Saudi Arabian Mental and Social Health Atlas (SAMHA), the purpose of which was to systematically identify and address the mental health needs of the population [28]. To ensure that goals were met, plans were made to conducted a 4-year follow-up study (SAMHA-2010), which has now been completed. ${ }^{1}$ One of the primary objectives of SAMHA has been to establish a strategic plan for the development of national mental health services that would increase mental health providers, improve the quality of mental health care, expand services for those with addictions, develop continuing education programs on mental health issues, conduct research to guide clinical interventions, establish quality indicators, increase social services to the mentally ill, and improve the infrastructure of mental health care throughout KSA. An immediate goal has been to increase the ratio of psychiatric beds per population to match the world average of 16 per 100,000, although it has remained at 12 per 100,000 in KSA from 2005 to 2010. Another goal has been to develop a procedures manual for all psychiatric hospitals in KSA. That manual, developed in 2012, contains information about hospital procedures, filing systems, and quality of care standards. A Mental Health Act (MHA), passed by the Saudi government in 2012, has now given the backing of law to some of these changes. All psychiatric hospitals in KSA now operate based on the 2012 MHA policies and procedures.

The plans above are being implemented by the General Administration for Mental Health and Social Services (GAMHSS) at the Ministry of Health (MOH) in Riyadh. Although the overall MOH budget has been increasing annually, there is still no independent budget for GAMHSS. Progress here is also being made, in that there are now separate budgets for two major mental health divisions, the Developmental and Behavioral Disorders in Children and the Saudi Society for the Care of Psychiatric Patients and Families. 
Today, most patients with serious mental health problems are treated in psychiatric hospitals that provide inpatient and outpatient services [28]. Patients with chronic mental disorder continue to be hospitalized for prolonged periods. Reasons for long-term stays included refusal by family to care for them, active psychiatric symptoms, need for rehabilitation, relative lack of community services, absence of halfway homes, and the legal issues related to premature discharge, which make psychiatrists reluctant to release them. Although the number of psychiatric outpatient clinics associated with general and specialty hospitals had expanded to nearly four dozen by 2006, a well-developed community mental health system (CMHS) still does not exist in KSA. Until that system develops (in the planning stage), most mental health needs of those living in the community will continue to be met by primary care physicians at the 1900 PHC centers in the country. Efforts are now being made to improve the training of medical practitioners to help them recognize and treat psychiatric problems, as well as train psychologists and social workers to screen for mental and emotional illness in these settings. There are also plans to develop more consultation-liaison services in tertiary care hospitals and to establish more psychiatric inpatient services in general hospitals [28]. Finally, pharmacists are being trained to monitor psychotropic drug use and educate patients about these drugs, since research has shown that such education improves drug adherence by $15 \%$ to $27 \%$ [29].

While there has been progress in training of primary care physicians (PCPs) to identify mental health problems in PHC centers, detection rates remain low. Earlier research reported that Saudi PCPs missed up to 90\% of patients with psychiatric problems [30] [31]. More recent research indicates improvement, although PCPs in KSA still miss more than half of those with psychiatric disorder [32]. While detect mental health problem by PCPs remains a problem in Saudi Arabia, detection rates in U.S. primary care settings are not much better [33]-[35]. Research has shown that Saudi PCPs can be trained to recognize mental disorders in medical patients [36]. Improved detection rates have been documented after only a 3 or 4-day course of didactic lectures with a clinical practice component, although this also depends to some degree on exposure to psychiatric training in medical school [37] [38].

There are many barriers that need to be overcome to increase the detection and treatment of mental health problems in KSA primary care settings. First, the presentation of psychiatric symptoms here is often manifested by —or mixed together with—medical symptoms (somatization, i.e., where stress/conflict is expressed in physical-like complaints). PCPs, then, must differentiate somatic symptoms that are medically unexplained from those that are influenced by psychological symptoms or are purely psychological in nature. Second, patients often believe that physical or psychiatric symptoms have supernatural causes, as emphasized by Dubovsky, and therefore seek help from spiritual or traditional healers-not allopathic physicians. Consider the results of a survey at a public hospital in Riyadh that examined attitudes and beliefs of hemodialysis patients [39]. Ninety-eight patients (58\% female, mean age 43) were asked what they thought caused their kidney disease and the most important factor responsible for their recovery. At the same time, 52 physicians and 60 hospital nurses were asked to predict patients' answers. In most cases (93\%), patients said the cause of their illness was the will of God, while only $1 \%$ said it was due to medical or physical causes and $6 \%$ to other causes. When doctors and nurses were asked to predict patients' responses, doctors said that $76 \%$ of patients would attribute the cause to the will of God, $12 \%$ to medical causes, and $12 \%$ to other causes. Among nurses, only $35 \%$ said that patients would say the will of God, $50 \%$ to medical/physical causes, and $15 \%$ to other causes. When patients were asked what they thought was the most important factor responsible for their recovery, 98\% said that the will of God was responsible, and interestingly, $0 \%$ said it was due to medical/physical treatments. Among doctors, $82 \%$ said that patients would attribute recovery to the will of God vs. $14 \%$ to medical/physical causes, whereas only $53 \%$ of nurses predicted that patients would say the will of God vs. $17 \%$ to medical/physical causes. Thus, traditional beliefs of patients may influence the presentation, diagnosis and treatment of psychiatric illness in medical settings, and medical doctors may be more likely than hospital nurses to be aware of this.

Patients not only attribute physical illness to religious causes, but often explain psychiatric symptoms the same way. Consider the results of a study that compared 150 outpatients (63\% male, mean age 32) seeing general practitioners in Riyadh with 131 outpatients (60\% male, mean age 39) being seen in primary care clinics in Sheffield, United Kingdom (UK). Patients were asked what they thought was the cause of auditory hallucinations (AH) and what the best treatment was for it [40]. Those in Riyadh vs. the UK gave the following responses as the cause: brain damage, $9 \%$ vs. $38 \%$; curse/magic, $17 \%$ vs. $2 \%$; Satan's/demons' voices, $34 \%$ vs. $5 \%$; symptoms of schizophrenia, $19 \%$ vs. $61 \%$; pretending, $17 \%$ vs. $7 \%$; bad childhood, $14 \%$ vs. $35 \%$; damage to ear, $10 \%$ vs. $23 \%$; and stress, $31 \%$ vs. $74 \%$ (all differences significant at $\mathrm{p}<0.01$ ). Concerning the best treatment for 
auditory hallucinations, responses were as follows: no treatment, $4 \%$ vs. $6 \%$; religious assistance, $66 \%$ vs. $11 \%$; surgery, $1 \%$ vs. $9 \%$; psychological therapy, $33 \%$ vs. $55 \%$; medication $5 \%$ vs. $22 \%$; medication + therapy, $23 \%$ vs. $63 \%$; and treatment of ear, $9 \%$ vs. $19 \%$ (most differences significant at $\mathrm{p}<0.01$ ).

The most recent data (2012) from Saudi Arabia on perceptions involving the cause of physical symptoms involves seizures. Researchers from the neurology section of the department of medicine at King Khalid National Guard Hospital surveyed 398 university graduated school teachers and undergraduate students at two universities in Jeddah [41]. When asked about the cause of epilepsy, $38 \%$ of teachers and $47 \%$ of students said it was a psychiatric illness. Possession by Jinns was reported by $40 \%$ of teachers and $50 \%$ of students to be the cause. With regard to treatments, reading the Qu'ran (ruqya) was considered a form of treatment by $68 \%$ of teachers and $82 \%$ of students. Cautery was felt to be an acceptable treatment by $10 \%$ of teachers and $16 \%$ of students. For those who believed that possession by Jinns was the cause of epilepsy, fewer indicated medication as a possible treatment $(\mathrm{p}<0.001)$ and more indicated that reading from the Qu'ran could cure the condition $(\mathrm{p}<$ 0.001). Bear in mind that these responses were from well-educated individuals in the current generation.

Thus, psychiatric symptoms may often present in primary care settings as either physical symptoms, or as symptoms thought to have religious causes (supernatural), making it difficult to correctly identify and diagnose mental health problems.

\section{Expansion of Mental Health Services}

The number of psychiatric hospitals in KSA has expanded nearly 10-fold over the past 30 years to 21 specialty hospitals today. These include three facilities, called "Al-Amal" hospitals, located in Jeddah, Riyadh, and Dammam that specialize in the treatment of addictions, and now a fourth facility, the 50-bed Al-Qaseem Psychiatric Rehabilitation Center in Buraidah that also treats addicts. Likewise, by 2012 many psychiatric hospitals and maternity and children hospitals had established child-adolescent psychiatric clincs in KSA. As noted above, the number of psychiatric beds in mental hospitals in KSA has remained relatively constant over the past 5-10 years at close to $3,000(12$ per 100,000) [1].

In comparison, the number of psychiatric beds in the U.S. at its peak in 1955 was 34 per 100,000. Since deinstitutionalization, which began in 1960, the number of psychiatric beds in the U.S. has now dropped to 14 per 100,000 (2012), the same ratio it was in the year 1850 [42]. Based on a consensus of 15 experts on psychiatric care in the U.S., the number of beds necessary to provide minimally adequate inpatient psychiatric services to the general population is 50 beds per 100,000 [43]. Given that deinstitutionalization has not yet occurred in KSA, the current number of psychiatric beds remains far below the recommended number.

The number of psychiatrists has also been expanding in KSA. In 1977, there were only three psychiatrists to serve the entire population of KSA [4]. By 1983, that number had increased about 10-fold, and by 2006 there were 205 psychiatrists serving a population of 23 million (0.9 per 100,000) [28]. By 2010 there were over 700 psychiatrists (3.0 per 100,000), including 380 who performed primarily outpatient psychiatry and 263 who worked in mental hospitals [1].

The number of psychologists, psychiatric nurses, and psychiatric social workers has also increased over time. According to SAMHA-2010, the latest figures indicate 1980 nurses working in outpatient facilities and 1176 in mental hospitals [1]. There were also 515 psychologists, social workers and occupational therapists at outpatient facilities and 611 working in mental hospitals. However, most nurses caring for the mentally ill did not start out with special training in psychiatry, and psychologists and social workers often do not have post-graduate degrees [28]. Several undergraduate and post-graduate training programs in psychology and counseling now exist at universities in KSA. These are University of Tabuk, King Khaled University in Abha, King Saud University in Riyadh, University of Dammam in the Eastern province, and Princess Noura Bint Abdulrahman University in Riyadh. Furthermore, 13 of KSA's 21 medical schools now offer post-graduate training for allied health disciplines including nurses, psychologists, social workers and counselors.

Although mental health services are expanding, much of the care for those with mental illness continues to take place in family settings today. The family is sacred in KSA and caring for family members is considered a religious obligation. Children do not leave the home until they are married, and elders are usually cared for within the family unit, not sent to a nursing home as in Western countries, resulting in large extended families living together. Mental health care also takes place within the nuclear and extended family, and such problems are often kept a secret. In Arabic societies as in most societies, including Western, individuals with mental illness and their families are often stigmatized, rejected and isolated. This is because mental illness is still asso- 
ciated with evil spirits, effects of the evil eye, magic, and punishment from God, or with violence, addiction and suicide [44]. Due to guilt and shame, family members often refuse to discuss mental problems with non-family members, including medical physicians and mental health professionals [45]. Furthermore, Islam promises special blessings on individuals and families who care for those who are sick, whether the illness be physical or mental. Islamic medicine that is based on the Qur' an and Hadiths holds that Muslims have a duty to care for the sick. As a result, families in KSA usually make every effort to do so. These Islamic values, however, may be slowly eroding.

\section{Services for Special Populations}

There is a particular need for mental health services to certain groups, particularly those with unique needs different from the general Saudi population.

Children and Adolescents. KSA has a relatively young population with a mean age of 26 years, compared to 28 for the world overall and 37 in the U.S. [46]. As noted earlier, $16 \%$ to $59 \%$ of secondary school students experience symptoms of significant mental distress. Thus, addressing the mental health needs of this age group is of utmost importance in assuring a future healthy and productive Saudi population.

There are now at least 21 child psychiatry clinics in KSA. Limited research, however, exists on the characteristics of patients seen in these settings. The most comprehensive study to date examined children and adolescents seen in three of those clinics [47]. All records of young persons evaluated during 2008 were reviewed $(\mathrm{n}=$ 899). The primary source of referral was from PHC centers (93\%); the mean age of participants was 9 (range 1 to 20); gender was evenly distributed between male and female; and most were Saudi nationals (92\%). Parental consanguinity, that is marriage between close relatives, was present in $50 \%$, and the mean number of siblings was 6 (range 1 to 18). The most common presenting symptoms were hyperactivity (43\%), poor school performance (33\%), delayed milestones (28\%), anxiety (18\%), attention and concentration problems (14\%), and impulsivity (13\%). Diagnoses were mental retardation (30\%), anxiety disorder (16\%), ADHD (13\%), autism spectrum disorder (13\%), mood disorder (4\%), school refusal (4\%), toileting problems (3\%), and psychosis (3\%). At the initial interview, $86 \%$ of these children and adolescents were prescribed one or more psychotropic medication (65\% one medication; $21 \%$ more than one). Polypharmacy (21\%) in these clinics was considerably lower than that reported in a study of adult Saudi psychiatric patients (85\%) [48]. Medication alone was not the only treatment offered to children and adolescents, and psychotherapy was recommended in 55\%. Good results of treatment were reported, with a "stable" outcome on follow-up in $82 \%$.

However, the above study only scratches the surface. Much more information is needed on the prevalence of psychiatric disorders in Saudi children and adolescents, detection rates, treatments, and outcomes, and much of this information will be collected during the 2013 Saudi National Mental Health Survey (at least those above the age of 15).

Older Adults. Older adults are usually first seen in PHCs and if they have psychiatric or behavioral problems, are referred to psychiatrists at general hospitals or teaching institutions. If rejected by their families, which is rare in this society, elders with mental or neurological problems such as dementia are placed in geriatric homes supported by the Ministry of Social Affairs. While the average age of the population in KSA is young, life expectancy is increasing rapidly. With an average life expectancy in KSA of 74 years, the percentage of the population over age 60 during the next 40 years will increase twice as rapidly as the rest of the world, expanding by nearly 4-fold from 5\% presently to $19 \%$ in 2050 [49]. Thus, over the next several decades the situation in KSA will soon be similar to that in the U.S., where persons over age 60 now make up $18 \%$ of the population [50].

The only information we have on rates of psychiatric disorders in older adults in KSA comes from two studies, both examining depression. As described earlier, a survey of nearly 8000 Saudi's age 60 or over from across KSA found that $39 \%$ scored at or above a cutoff of 10 on the Geriatric Depression Scale (GDS) [51]. The second study involved home-based interviews with 810 persons age 65 or over living in Abha, reporting that 18\% scored at or above the established cutoff score on the GDS short-version [52]. Thus, based on the available data at this time, rates of significant depression among older adults range from $18 \%$ to $39 \%$. To our knowledge, research on psychiatric problems other than depression among older adults in KSA is non-existent. Given the increased number of elders projected over the next 40 years, it is essential that psychiatrists receive specialized training on the psychiatric problems of older adults in this country. The SNMHS will provide updated epidemiological data on psychiatric disorders in this age group.

Substance Abuse. The consumption of alcohol and use of illegal drugs is forbidden in KSA. Data from the 
WHO suggest that the per capita consumption of pure alcohol between 1977 and 1998 by persons age 15 or over in KSA ranged from 0.1 to 0.4 litres per year [53]. Alcohol consumption peaked in 1985 at 0.4 litres and then dropped, remaining relatively stable between 1992 and 1998 at less than 0.1 litres per person/year. "Unrecorded consumption" in 1995, however, was estimated at 0.6 litres per year per capita, or about six times higher than recorded consumption [54]. Most alcohol is consumed by only a small percent of the population, with $97 \%$ of Saudi's abstaining from alcohol entirely (95\% of men and $99 \%$ of women). Admittedly, those figures do not include unrecorded consumption. The only other research on alcohol use in KSA comes from a survey of college students. In 2009, researchers surveyed 357 male students ages 18 to 24 enrolled in the College of Health Sciences at Qassim University near Buraidah, of whom 4\% admitted using alcohol [55].

There is even less information on drug use in KSA, and most of this comes from the early 1990's. One survey of 669 students at King Saud University in Riyadh found that 3.8\% reported personal experiences with drugs [56]. Another study of 1,778 Saudi male seconday school students in eastern KSA reported that $5.3 \%$ used volatile solvents such as petrol/benzene, paints, or lighter fluid at some point in their lives [57]. Tobacco use, although not illegal, is also a problem in KSA, especially among children and adolescents. In a survey of 1,830 boys ages 13 - 15 in secondary schools in Riyadh, researchers found that 35\% had smoked cigarettes at some time in the past and $11 \%$ admitted to having smoked within the past 30 days [58]. These estimates are similar to those among adults in KSA [59]. Among boys who had smoked, 44\% first tried smoking before age 11 . Other tobacco products including shisha, moasil, or chewing tobacco were used by $13 \%$ within the past month. The strongest predictor of smoking was whether close friends smoked.

Information on alcohol and drug use is also available from research on those seeking psychiatric treatment. In the early 1990's, one study found that only $1.7 \%$ of patients admitted to a psychiatric hospital in Jeddah had alcohol or drug use disorders (of which $97.3 \%$ were in men) [60]. There is also data from admissions to substance abuse treatment centers. In a study conducted in the late 1990's at the Al-Amal Hospital in Riyadh, about 25\% of patients reported using alcohol [61], and more recent data (2006) suggest little change in that proportion [62]. However, a shift in the types of illegal drugs used by psychiatric patients has been observed. As reviewed previously, a 1994 study of 116 patients admitted to Al-Amal Hospital in Dammam reported that 84\% used heroin alone in or in combination with other drugs, $31 \%$ used alcohol, $26 \%$ used cannabis, and $10 \%$ used stimulants [63]. A more recent review of 12,743 patients at the same Al-Amal Hospital in Dammam between 1986 and 2006 reported a change in drug of choice [62]. Admissions during the first decade (1986-1996) were for heroin (51\%), alcohol (27\%), cannabis (18\%), sedatives (15\%), amphetamines (12\%) and volatile substance use (6\%), which are similar to the 1994 study above. In the second decade (1997-2006), however, patients were more likely to be admitted for amphetamines (48\%) and cannabis (47\%), but less likely for heroin (23\%), sedatives (7\%), or volatile substances (3\%). Researchers concluded that considerable shifts had occurred in the types of drugs being abused, likely reflecting changes in the pattern of use in the community.

Medically Ill. The psychiatric problems of those with medical illness are usually related to the disability and quality of life changes caused by their physical conditions. These changes give rise to anxiety, depression, and organic mental disorders, along with other psychiatric problems. Consultation-liaison (CL) psychiatry is the specialty that deals with psychiatric disorders in medically ill patients, and often involves consultation on inpatient units at general hospitals. Several studies in KSA have now examined the range of problems that CL psychiatrists are likely to encounter in hospitalized medical patients. For example, Alhamad and colleagues reviewed the records of 5,264 patients admitted to the King Fahad General Hospital in Jeddah between July and December 1994 [64]. Psychiatry consults were requested on 3.9\%. There were 188 referrals (3.8\% of all admissions) from the inpatient services and 18 referrals (6.3\%) from the emergency room. Referred patients tended to be male (59\%) and younger (mean age was 37). The highest rate of referral came from the nephrology/hemodialysis unit (8\%) and the lowest from surgery (2\%). Reasons for referral based on diagnoses made by medical providers and psychiatric diagnoses made by CL psychiatrists after referral are listed in the Table 1 (study 1). The most common overall question on referral was help with diagnosis (50\%), and the next most common reason was help with management (28\%).

In a second report from these researchers, 88 physicians who referred patients to the CL service were questioned about their usual practice regarding CL referrals and why [65]. The majority (57\%) said they had only needed psychiatric consultations once or twice, whereas $18 \%$ said they never needed such consultations and $24 \%$ said they had consulted psychiatrists more than three times. Note that the time frame for the question was since graduating from medical school, an average of 5 years previously. For psychotic delusions, nephrologists 
Table 1. Reasons for consultation-liaison referral and psychiatric diagnoses made after referral in Saudi Arabia and the United States.

\begin{tabular}{|c|c|c|c|c|}
\hline & \multicolumn{2}{|c|}{ Saudi Arabia } & \multicolumn{2}{|c|}{ United States } \\
\hline & $\underline{\mathrm{St} \# 1}$ & $\underline{\mathrm{St} \# 2}$ & $\underline{\mathrm{St} \# 3}$ & $\underline{\text { St \#4 }}$ \\
\hline$\underline{\text { Reason for Referral }}$ & $\%$ & $\%$ & $\%$ & $\%$ \\
\hline Depression & 31 & 33 & 35 & 27 \\
\hline Anxiety & 17 & 10 & 6 & - \\
\hline Psychosis & 13 & 2 & 6 & - \\
\hline Organic brain syndrome/delirium & 8 & 4 & 8 & 11 \\
\hline Substance abuse & 13 & 1 & 28 & 12 \\
\hline Personality disorder & 1 & - & - & - \\
\hline Suicidal behavior & - & 3 & 12 & 13 \\
\hline Behavioral problem & - & 14 & 4 & - \\
\hline Other & 17 & 33 & 18 & 37 \\
\hline \multicolumn{5}{|l|}{$\underline{\text { Diagnosis by Psychiatrist }}$} \\
\hline Depression & 34 & 21 & 55 & 35 \\
\hline Adjustment disorder & - & 7 & 9 & 11 \\
\hline Bipolar disorder & - & 6 & 7 & 5 \\
\hline Anxiety & 13 & 12 & 14 & 12 \\
\hline Psychosis & 7 & 4 & 9 & 10 \\
\hline Organic brain syndrome/delirium & 16 & 9 & 24 & 16 \\
\hline Substance abuse & 11 & 3 & 39 & 36 \\
\hline Personality disorder & 7 & 6 & 5 & 2 \\
\hline Other & 13 & 12 & 5 & 8 \\
\hline No diagnosis & - & 21 & 2 & 8 \\
\hline
\end{tabular}

St $\# 1$ = study $\# 1,{ }^{65} \mathrm{St} \# 2$ = study $\# 2,{ }^{66} \mathrm{St} \# 3$ = study $\# 3,{ }^{68} \mathrm{St} \# 4$ = study $\# 4{ }^{69}$; percentages in some columns add up to more than $100 \%$ because more than one reason for referral or psychiatric diagnosis was reported for each patient.

were most likely to seek psychiatric consultation (63\%), followed by surgeons (58\%), internists (55\%), and orthopedic surgeons (29\%). The majority of referring physicians (56\%) said they found psychiatric consultations helpful in managing patients, whereas the remaining $44 \%$ said they found it only sometimes or not at all helpful. When asked whether they would consider prescribing psychiatric medications to their patients, 50\% said they would never do so, while $43 \%$ said they would possibly prescribe, and $7 \%$ said they would likely prescribe. Interestingly, two-thirds (65\%) considered benzodiazepines the safest psychotropic drug, 14\% said that antipsychotics were safest, and 5\% said tricyclic antidepressants were safest.

More recently, researchers examined 264 patients consecutively referred to the CL services of the 800-bed King Khaled University Hospital in Riyadh [66]. Referred patients were more likely to be female (65\%), young (mean age 35), and those with longer hospital stays (average 17 days). Referrals were most likely from medicine (45\%), surgery (25\%), obstetrics-gynecology (21\%), and intensive care (6\%). Reasons for referral and psychiatric diagnoses made are listed in the Table 1 (study 2). There is also considerable medical co-morbidity in patients referred from PHC centers and from general hospitals to psychiatric facilities, requiring that Saudi psychiatrists be able to distinguish symptoms of medical illness from psychiatric disease [67].

For comparison, research in the U.S. has also examined referral sources, reasons for referral, and diagnoses after referral. A study of 541 consecutive CL referrals (3.1\% of all admissions) at a Midwestern general hospital in 2001 found that the most common sources of referral were from medicine (43\%), family medicine (23\%), surgery (18\%), and intensive care (11\%) [68]. Reasons for referral and psychiatric diagnoses after evaluation are listed in Table 1 (study 3). A second study that examined 961 consecutive CL referrals at a large Northeastern general hospital (3.1\% of all admissions) categorized referrals by age group. For non-geriatric patients, reasons for referral and psychiatric diagnoses after evaluation (DSM-IV-TR) are listed in Table 1 (study 4) [69]. In summary, then, other than fewer referrals for substance abuse and suicide concerns in KSA, CL psychiatrists in KSA and the U.S. tend to see similar patients, and referral rates and referring services are similar as well. 


\section{The Future}

In discussing the future of mental health care in KSA, it is important to consider how present-day medical students feel toward psychiatry and what type of training in psychiatry are they receiving. This will help predict the number of future psychiatrists in Saudi Arabia. Medical school in KSA is a 6-year program beginning after one year of general university studies that follows secondary school. In a recent study of 441 medical students at King Khalid University College of Medicine in Abha, researchers found that only $2 \%$ were planning to pursue a career in psychiatry, with women outnumbering men by 3 to 1 [70]. The percentage of students choosing psychiatry increased from $1.5 \%$ during the 1 st and 2 nd years of medical school to $4 \%$ during the 4th and 5th years. This pattern is not greatly different from medical student attitudes toward psychiatry in the U.S. In 1999-2003, researchers asked 942 medical students at three representative medical schools in the U.S. to choose a specialty. [71]. Among those in their 1st year, $1 \%$ chose psychiatry, compared to $3 \%$ in their 4 th year.

One of the most important factors shown to influence student attitudes toward psychiatry is taking a 4-week rotation in this area. One study at King Faisal University College of Medicine in Al-Hassa found that before exposure to psychiatric training, only a bare majority of medical students agreed that psychiatric consultation was often helpful (59\%) and that psychiatry was a rapidly expanding frontier (56\%) [72]. After taking a rotation in psychiatry, those percentages increased to $74 \%$ and $89 \%$, respectively. Furthermore, $85 \%$ of students said that psychiatric residents were good role models and $91 \%$ that most other house staff were respectful of psychiatry. The importance of exposing students to psychiatry as part of their required training in medical school cannot be overemphasized [73]. Of the 21 medical schools in KSA, all currently require a 3 - 12 week rotation in psychiatry.

Residency training in psychiatry was not formally established in KSA until 1997 [74]. Since then, three 4-year programs have now started in Riyadh, Jeddah, and Dammam. Each of these programs graduate 6 to 10 residents per year. After graduation, they must pass the boards in psychiatry in order to practice in KSA. Although recertification is not required as in the U.S., continuing medical education (CME) credits must be acquired to maintain licensure. For renewal of certification by the Saudi Commission for Health Specialties, ninety CME hours are required every three years, plus completion of a basic course in cardiopulmonary resuscitation. There are now at least eight formal departments of psychiatry at universities in KSA, although only three have psychiatry residency programs.

While the number of residency programs has increased, sub-specialty programs in psychiatry remain under-developed. Most Saudi psychiatrists who wish to obtain fellowship training in addiction, geriatric, forensic, or consultation-liaison psychiatry go to Western countries, primarily Canada, U.S. or the U.K. To our knowledge there is only one accredited fellowship available in KSA, which is a child-adolescent psychiatry fellowship at the National Guard Hospital in Riyadh, where 4 - 6 fellows have now completed the program. There will be a second child-adolescent fellowship starting soon at King Saud bin Abdulaziz University in Riyadh. To our knowledge, there are no formal fellowships in addiction, forensic, consultation-liaison, or geriatric psychiatry in KSA. While there have been recent developments in terms of consultation-liaison and addiction psychiatry training, no progress has been made in geriatric psychiatry training. Psychiatrists in KSA cannot continue to rely on their fellowship training from Western countries, as these training environments often have no appreciation for the unique experiences and cultural background of those with mental problems living in Saudi Arabia.

\section{A Research Agenda}

Research is needed in KSA to identify those with mental health problems, determine the demographic, social, and behavioral characteristics that increase or decrease risk of mental disorder, and discover the most effective treatments that Saudis are willing to accept given their unique social, cultural, and religious backgrounds. These interventions may include psychotherapies, psychotropics, other biological therapies, or complementary and alternative therapies. Research is also needed on mental health care providers, including the latest information on numbers of psychiatrists, psychologists, psychiatric social workers, nurses, and counselors, and the kind of training that they have received. This information is crucial for guiding the development and funding of training programs necessary to meet the mental health needs of the entire population.

Fortunately, mental health research has increased in priority over the past several decades in KSA. Although almost non-existent before 1975, a number of studies have been published in the past 10 years. A survey of published mental health research between 1987 and 2002 in the Arab world found that among the five countries of 
Egypt, Lebanon, Saudi Arabia, Kuwait, and United Arab Emirates, the volume of research publications from Saudi Arabia was second highest, surpassed only by Kuwait [75]. More recently, researchers found that mental health publications per year from KSA increased from 0 - 1 between 1966 to 1985 to 18 between 1996 to 2006, second only to Egypt among 21 Arab countries [76]. Mental health research in treatment resistent depression has been a particular interest of Saudi researchers in recent years [77] [78].

Nevertheless, KSA still remains far behind Western countries in terms of research output in the psychological and behavioral sciences. Publications on mental health from the U.S. and U.K. during only a 10 -year period between 1992 and 2001 numbered approximately 59,000. Compare this to 299 publications from KSA during the 40-year period between 1966 and 2006.

Thus, while much progress has been made, much remains to be done in terms of mental health research, and there are reasons to be optimistic. A 2009 national competency framework developed for Saudi medical schools has emphasized the importance of research, with an entire section devoted to the doctor and research. Under this section were the topics, "Introduction to medical research and appreciation of value of research in medical field" and "Conducting medical research" [79]. This means that research in medical schools, including research on mental health, will be a focus in the future. Similarly, King Abdulaziz City for Science and Technology has funded a project to prioritize health research in the KSA, and asked King Faisal Specialist Hospital and Research Center in Riyadh to set research priorities at the national level. A national committee was formed, including one of the authors of this paper (NAQ), to establish research priorities for the country. This group identified the following priority areas for medical research: non-communicable diseases (cardiovascular, diabetes, cancer, allergy/asthma, neurodegenerative disease), communicable diseases, genetics, cell therapy, disability, and environmenetal health. Mental health research is emphasized in two of these categories, neurodegenerative disease and disability [80].

\section{Cultural and Religious Influences}

Given the importance and impact of cultural and religious influences on Saudi's as well as on expatriates that make up nearly one-third of the population [81], mental health must be understood in this context and mental health care delivered in a way that is respectful of long-held sacred traditions and belief systems. The population of KSA is rich and diversified with people from all over the world living and working there. The three major cultural influences in this country are its Islamic values, Islamic heritage and Bedouin traditions. For the past 5000 years, Arab merchants have been part of a trade network that extends north to nations around the Mediterranean sea, Persian gulf, and South Asia and south to the African continent. For many Arabs, traditional ways of Bedouin life, oasis-dwelling farmering, coastal fishing, craftsmanship and art, and long-distance trading remain influential. Regional and kin-based tribal and clan identities continue to be very important.

Since the 7th century, the influence of Islam has been felt in every aspect of work, community, and family life. Islamic law, called Sharia, rules in KSA. Ramadan is the holiest season of the year, and there is no eating, drinking, smoking, or sexual activity from dawn (sahoor) to dusk (iftar) during this month. The Hajj to Mecca takes place every year in the ZulHajja Arabic month, when millions from all over the world participate in this religious ritual. Every day, throughout the year, all activities cease and businesses shut down for approximately 20 minutes at dawn, noon, mid-afternoon, sunset, and shortly after sunset, as the call for prayer goes out from every mosque. All stop to pray and worship. Men are required to pray on Friday at noon at the mosque and listen to the teachings of the Imam, called khutba. Saudi's believe that prayer and reading of the Holy Qur'an is a central aspect of maintaining mental health and treating mental problems, and by extension, many believe these are also necessary for maintaining physical health and treating medical problems.

Interestingly, in contrast to Arabic folk lore, Islam does not explain all mental illnesses as resulting from supernatural causes. At least one early Muslim scholar, Ibn Sina, rejected the notion that evil spirits caused mental illness [82]. Islamic law protects those with mental illness, and if family cannot do so, a guardian is appointed to protect the person's property. Mentally ill persons, especially those with severe persistent psychotic disorders, are not required to perform the five daily prayers or to fast [83]. "Not guilty by reason of insanity" was a concept in Islam many centuries before Western countries adopted it as a legal defense, and those deemed "insane" were often not held accountable for their crimes [84].

Islamic law also dictates social customs. Women are required to cover their entire bodies with an abaya (black robes and face covering) as a display of modesty; cannot drive; may not converse with men in public except 


\begin{tabular}{lll|l|l|l|}
1932 & & & \\
\hline
\end{tabular}

\begin{tabular}{ll|l|l|l|l|}
2011 & & & & \\
\hline
\end{tabular}

Figure 1. Past, present and future of mental health system in Saudi Arabia.

with husbands, brothers, and fathers; and may not mingle in public unless they are married or in a formal educational environment and here too, women are usually physically separated from men within the classroom in seminars, workshops, conferences and offices. If a family escort (mehrum) is present (i.e., father, mother, husband, sibling), a woman may meet with a male psychiatrist, psychologist, psychiatric social worker or counselor, although there may be no physical contact including hand-shaking. The expressions of mental illness are heavily influenced by every one of these religious and cultural factors, and approaches to mental health care must take them into account [85].

\section{Conclusion}

There has been remarkable progress in the recognition and treatment of mental health disorders over the past 60 years in Saudi Arabia, especially in the last two decades (Figure 1). The mental health system is making long strides toward addressing the mental health needs of its people. There is still a way to go in extending care to the entire population including expatriates, in developing training programs in Saudi medical centers and academic institutions particularly fellowship training in psychiatry subspecialties, and in conducting research to guide efforts to modernize the mental health care system. There are now plans to systematize, standardize, and expand mental health services across the country and to develop specialty training programs in every area, from childadolescent to geriatric to addictions to consultation-liaison to forensic psychiatry. There is a tremendous opportunity for systematic research on the identification, course, and treatment of mental and emotional disorders in KSA. However, as psychiatry moves rapidly into the 21st century in Saudi Arabia, one cannot ignore the dominating influences that culture, family, and religion continue to have on the understanding, diagnosis, and treatment of mental disorders in this country.

\section{References}

[1] Qureshi, N.A., Al-Habeeb, A.A. and Koenig, H.G. (2013) Mental Health System in Saudi Arabia: An Overview. Neuropsychiatric Disease and Treatment, 9, 1121-1135.

[2] Koenig, H.G., Al Zaben, F., Sehlo, M.G., Khalifa, D.A. and Shaheen Al Ahwal, M. (2013) Current State of Psychiatry in Saudi Arabia. International Journal of Psychiatry in Medicine, 46, 221-240. http://dx.doi.org/10.2190/PM.46.3.a

[3] Pasnau, R.O. and Hartmann, L. (1983) Psychiatry in the Kingdom of Saudi Arabia. American Journal of Psychiatry, 140, 1493-1494.

[4] Dubovsky, S.L. (1983) Psychiatry in Saudi Arabia. American Journal of Psychiatry, 140, 1455-1459.

[5] American Psychiatric Association (2013) Diagnostic and Statistical Manual of Mental Disorders, 5th Edition: DSM-5. American Psychiatric Publishing, Arlington. 
[6] Qureshi, N.A., al-Amri, A.H., Abdelgadir, H. and El-Haraka, E.A. (1998) Traditional Cautery among Psychiatric Patients in Saudi Arabia. Transcultural Psychiatry, 35, 75-83. http://dx.doi.org/10.1177/136346159803500103

[7] Al-Shammari, S.A. and Al-Subaie, A. (1999) Prevalence and Correlates of Depression among Saudi Elderly. International Journal of Geriatric Psychiatry, 14, 739-747. http://dx.doi.org/10.1002/(SICI)1099-1166(199909)14:9<739::AID-GPS998>3.0.CO;2-1

[8] Abdel-Fattah, M.M. and Asal, A.R.A. (2007) Prevalence, Symptomatology, and Risk Factors for Depression among High School Students in Saudi Arabia. Neurosciences, 12, 8-16.

[9] Al-Gelban, K.S. (2006) Depression, Anxiety and Stress among Saudi Adolescent School Boys. Journal of the Royal Society for the Promotion of Health, 127, 1-5.

[10] Al-Gelban, K.S. (2009) Prevalence of Psychological Symptoms in Saudi Secondary School girls in Abha, Saudi Arabia. Annals of Saudi Medicine, 29, 275-279. http://dx.doi.org/10.4103/0256-4947.55308

[11] Merikangas, K.R., He, J.P., Burstein, M., Swanson, S., Avenevoli, S., Cui, L., Benjet, C., Georgiades, K., Swensen, J. (2010) Lifetime Prevalence of Mental Disorders in U.S. Adolescents: Results from the National Comorbidit Survey Replication-Adolescent Supplement (NCs-A). Journal of the American Academy of Child and Adolescent Psychiatry, 49, 980-989. http://dx.doi.org/10.1016/j.jaac.2010.05.017

[12] Becker, S., Al Zaid, K. and Al Faris, E. (2002) Screening for Somatization and Depression in Saudi Arabia: A Validation Study of the PHQ in Primary Care. International Journal of Psychiatry in Medicine, 32, 271-283. http://dx.doi.org/10.2190/XTDD-8L18-P9E0-JYRV

[13] Al-Khathami, A.D. and Ogbeide, D.O. (2002) Prevalence of Mental Illness among Saudi Adult Primary Care Patients in Central Saudi Arabia. Saudi Medical Journal, 23, 721-724.

[14] Al-Faris, E., Al-Subaie, A., Khoja, T., Al-Ansary, L., Abdul-Raheem, F., Al-Hamdan, N., Al-Mazrou, Y., Abdul-Moneim, H. and El Khwsky, F. (1997) Training Primary Helath Care Physicians in Saudi Arabia to Recognize Psychiatric Illness. Acta Psychiatrica Scandinavica, 96, 439-444. http://dx.doi.org/10.1111/j.1600-0447.1997.tb09945.x

[15] Huang, F.Y., Chung, H., Kroenke, K., Delucchi, K.L. and Spitzer, R.L. (2006) Using the Patient Health Questionnaire9 to measure depression among racially and ethnically diverse primary care patients. Journal of General Internal Medicine, 21, 547-552. http://dx.doi.org/10.1111/j.1525-1497.2006.00409.x

[16] Olfson, M., Shea, S., Feder, A., Fuentes, M., Nomura, Y., Gameroff, M. and Weissman, M.M. (2000) Prevalence of Anxiety, Depression, and Substance Use Disorders in an Urban General Medicine Practice. Archives of Family Medicine, 9, 876-883. http://dx.doi.org/10.1001/archfami.9.9.876

[17] The Saudi National Mental Health Survey (SNMHS) (2010) Prince Salman Center for Disability Research, Riyadh. http://www.pscdr.org.sa/en/research/projects/Documents/SNMHS Program update.pdf

[18] Kessler, R.C., McGonagle, K.A., Zhao, S., Nelson, C.B., Hughes, M., Eshleman, S., Wittchen H.U. and Kendler, K.S. (1994) Lifetime and 12-Month Prevalence of DSM-III-R Psychiatric Disorders in the United States: Results from the National Comorbidity Survey. Archives of General Psychiatry, 51, 8-19. http://dx.doi.org/10.1001/archpsyc.1994.03950010008002

[19] Kessler, R.C., Ormel, J., Petukhova, M., McLaughlin, K.A., Green, J.G., Russo, L.J., et al. (2011) Development of Lifetime Comorbidity in the World Health Organization World Mental Health Surveys. Archives of General Psychiatry, 68, 90-100. http://dx.doi.org/10.1001/archgenpsychiatry.2010.180

[20] Qureshi, N.A., Al Quraishi, N.Y. and Hegazy, I.S. (1991) Some Characteristics of Mental Patients Admitted to a Psychiatric Hospital. Arab Journal of Psychiatry, 2, 146-158.

[21] Hafeiz, H.B. (1995) Socio-Demographic Correlates and Pattern of Drug Abuse in Eastern Saudi Arabia. Drug and Alcohol Dependence, 38, 255-259. http://dx.doi.org/10.1016/0376-8716(95)90001-X

[22] Al-Sharqi, A.M., Sherra, K.S., Al-Habeeb, A.A. and Qureshi, N.A. (2012) Suicidal and Self-Injurious Behavior among Patients with Alcohol and Drug Abuse. Substance Abuse and Rehabilitation, 3, 91-99.

[23] AbuMadini, M.S. and Rahim, S.I. (2002) Psychiatric Admission in a General Hospital. Patients Profile and Patterns of Service Utilization over a Decade. Saudi Medical Journal, 23, 44-50.

[24] World Health Organization (2001) Atlas: Mental Health Resources in the World. World Health Organization, Geneva.

[25] Qureshi, N.A., Van Der Molen, H.T., Schmidt, H.G., Al-Habeeb, T.A. and Magzoub, M.E.M. (2009) Criteria for a Good Referral System for Psychiatric Patients: The View from Saudi Arabia. Eastern Mediterranean Health Journal, 15, 1580-1595.

[26] Ministry of Health (2010) Ministry of Health Portal: Statistics Book. http://www.moh.gov.sa/en/Ministry/Statistics/Book/Pages/default.aspx

[27] Qureshi, N.A., Al-Habeeb, T.A., Al-Ghamby, Y.S., Magzoub, M.M. and Schmidt, H. (2001). Psychiatric Referral in Primary Care and General Hospitals in Qassim Region, Saudi Arabia. Saudi Medical Journal, 22, 619-624. 
[28] Al-Habeeb, A.A. and Qureshi, N.A. (2010) Mental and Social Health Atlas I in Saudi Arabia: 2007-08. Eastern Mediterranean Health Journal, 16, 570-577.

[29] Al-Jumah, K.A. and Qureshi, N.A. (2012) Impact of Pharmacist Interventions on Patients' Adherence to Antidepressants and Patient-Reported Outcomes: A Systematic Review. Patient Preference and Adherence, 6, 87-100.

[30] Al Faris, E. and Al Hamid, A. (1995) Hidden and Conspicuous Psychiatric Morbidity in Saudi Primary Health Care. Arab Journal of Psychiatry, 6, 162-175.

[31] Al-Faris, E. (1998) Towards a Campaign to Combat psychological Disorders in the Community. Annals of Saudi Medicine, 83, 205-207.

[32] Becker, S.M. (2004) Detection of Somatization and Depression in Primary Care in Saudi Arabia. Social Psychiatry and Psychiatric Epidemiology, 39, 962-966. http://dx.doi.org/10.1007/s00127-004-0835-4

[33] Borowasky, S.J., Rubenstein, L.V., Meredith, L.S., Camp, P., Jackson-Triche, M. and Wells, K.B. (2000) Who Is at Risk of Nondetection of Mental Health Problems in Primary Care? Journal of General Internal Medicine, 15, 381-388. http://dx.doi.org/10.1046/j.1525-1497.2000.12088.x

[34] Edlund, M.J., Unützer, J. and Wells, K.B. (2004) Clinician Screening and Treatment of Alcohol, Drug, and Mental Problems in Primary Care: Results from Healthcare for Communities. Medical Care, 42, 1158-1166. http://dx.doi.org/10.1097/00005650-200412000-00002

[35] Kessler, R.C., Demler, O., Frank, R.G., Olfson, M., Pincus, H.A., Walters, E.E., Wang, P., Wells, K.B. and Zaslavsky, A.M. (2005) Prevalence and Treatment of Mental Disorders, 1990-2003. New England Journal of Medicine, 352, 2515-2523. http://dx.doi.org/10.1056/NEJMsa043266

[36] Al-Faris, E., Al-Subaie, A., Khoja, T., Al-Ansary, L., Abdul-Raheem, F., Al-Hamdan, N., Al-Mazrou, Y., Abdul-Moneim, H. and Khwsky, F.E. (1997) Training Primary Health Care Physicians in Saudi Arabia to Recognize Psychiatric Illness. Acta Psychiatrica Scandinavica, 96, 439-444. http://dx.doi.org/10.1111/j.1600-0447.1997.tb09945.x

[37] Qureshi, N.A., Van Der Molen, H., Schmidt, H.G., Al-Habeeb, T.A. and Magzoub, M.E.M. (2006) Effectiveness of Training Programme for Primary Care Physicians Directed at the Enhancement of Their Psychiatric Knowledge in Saudi Arabia. Education for Health, 19, 52-60.

[38] Al-Khathami, A.D., Mangoud, A.M., Rahim, I.A. and AbuMadini, M.S. (2011) Traditional Mental Health Training’s Effect on Primary Care Physicians in Saudi Arabia. Mental Health in Family Medicine, 8, 3-5.

[39] Harakati, M., Shaeen, F., Tamim, H., Taher, S., Al, Q.A. and Al, S.A. (2011) Saudi Patients and Health Care Providers: Divergent Perceptions of Illnesses and Their Symptoms. Anthropology of the Middle East, 6, 35-46. http://dx.doi.org/10.3167/ame.2011.060104

[40] Wahass, S. and Kent, G. (1997) A Comparison of Public Attitudes in Britain and Saudi Arabia towards Auditory Hallucinations. International Journal of Social Psychiatry, 43, 175-183. http://dx.doi.org/10.1177/002076409704300303

[41] Obeid, T., Abulaban, A., Al-Hantani, F., Al-Malki, A.R. and Al-Ghamdi, A. (2012) Possession by “Jinn” as a Cause of Epilepsy (Saraa): A Study from Saudi Arabia. Seizure, 21, 245-249. http://dx.doi.org/10.1016/j.seizure.2012.01.001

[42] Treatment Advocacy Center (2012) Psychiatric Bed Numbers Plummet to 1850 Levels, Putting Patients, the Public at Risk: New Study Calls for Moratorium on Hospital Closures. Catalyst, 1, 8-9. http://www.treatmentadvocacycenter.org/storage/documents/catalysts/fall-2012-catalyst.pdf

[43] Torrey, E.F., Entsminger, K., Geller, J., Stanley, J. and Jaffe, D.J. (2008) The Shortage of Public Hospital Beds for Mentally Ill Persons: A Report of the Treatment Advocacy Center. Treatment Advocacy Center, Arlington. http://www.treatmentadvocacycenter.org/storage/documents/the_shortage_of_publichospital_beds.pdf

[44] Pridmore, S. and Pasha, M.I. (2004) Psychiatry and Islam. Australasian Psychiatry, 12, 380-385. http://dx.doi.org/10.1111/j.1440-1665.2004.02131.x

[45] Farooqi, Y.N. (2006) Traditional Healing Practices Sought by Muslim Psychiatric Patients in Lahore, Pakistan. International Journal of Disability, Development and Education, 53, 401-415. http://dx.doi.org/10.1080/10349120601008530

[46] U.S. Global Health Policy (2012) Population under Age 15 (Percent). http://kff.org/global-indicator/population-under-age-15/

[47] Al-Habeeb, A.A., Qureshi, N.A. and Al-Maliki TA (2012) Pattern of Child and Adolescent Psychiatric Disorders among Patients Consulting Publicly-Funded Child Psychiatric Clinics in Saudi Arabia. Eastern Mediterranean Health Journal, 18, 112-119.

[48] Al-Ghamdy, Y.S., Qureshi, N.A., Abdelghadir, M.H., Al-Habeeb, T.A. and Ahmad, S.A. (1999) A Study of Psychotropic Drug Prescriptions in Al-Qassim Region, KSA. Eastern Mediterranean Health Journal, 5, 27-34.

[49] Mirkin, B. (2010) Population Levels, Trends and Policies in the Arab Region. Challenges and Opportunities. United National Development Programme, Regional Bureau of Arab States, Arab Human Development Report, 33. 
http://www.arab-hdr.org/publications/other/ahdrps/paper01-en.pdf

[50] Administration on Aging (2008) Projected Future Growth of the Older Population: By Age 1900-2050, Persons 60 and Older. http://www.aoa.gov/AoARoot/Aging_Statistics/future_growth/future_growth.aspx

[51] Al-Shammari, S.A. and Al-Subaie, A. (1999) Prevalence and Correlates of Depression among Saudi Elderly. International Journal of Geriatric Psychiatry, 14, 739-747. http://dx.doi.org/10.1002/(SICI)1099-1166(199909)14:9<739::AID-GPS998>3.0.CO;2-1

[52] Abolfotouch, M.A., Daffallah, A.A., Khan, M.H., Khattab, M.S. and Abdulmoneim, I. (2001) Psycosocial Assessment of Geriatric Subjects in Abha City, Saudi Arabia. Eastern Mediterranean Health Journal, 7, 481-491.

[53] World Health Organization (2004) Saudi Arabia. http://www.who.int/substance abuse/publications/en/saudi arabia.pdf

[54] World Health Organization (2003) World Health Organization Regional Office for the Eastern Mediterranean Questionnaire for Regional Situation Analysis on Drug Abuse. WHO Regional Office for the Eastern Mediterranean, Cairo. http://www.who.int/substance_abuse/publications/global_status_report_2004_overview.pdf

[55] Al-Rethaiaa, A.S., Fahmy, A.A. and Al-Shwaiyat, N.M. (2010) Obesity and Eating Habits among College Students in Saudi Arabia: A Cross-Sectional Study. Nutrition Journal, 9, 39. http://dx.doi.org/10.1186/1475-2891-9-39

[56] Al-Subaie, A.S. and Al-Hajjaj, M.S (1995) Awareness and Knowledge of Saudi University Students about Drug Dependence. Saudi Medical Journal, 16, 326-329.

[57] Al-Umran, K., Mahgoub, O.M. and Qurashi, N.Y. (1993) Volatile Substance Abuse among School Students of Eastern Saudi Arabia. Annals of Saudi Medicine, 13, 520-524.

[58] Al-bedah, A.M. and Qureshi, N.A. (2011) The Global Youth Tobacco Survey: 2001-2002 in Riyadh Region, the Kingdom of Saudi Arabia. Substance Abuse and Rehabilitation, 2, 197-204.

[59] World Health Organization Eastern Mediterranean Region (2011) Saudi Arabia: Country Statistics. http://rho.emro.who.int/rhodata/?theme=country

[60] Osman, A.A. (1992) Substance Abuse among Patients Attending a Psychiatric Hospital in Jeddah: A Descriptive Study. Annals of Saudi Medicine, 12, 289-293.

[61] Al-Nahedh, N. (1999) Relapse among Substance-Abuse Patients in Riyadh, Saudi Arabia. Eastern Mediterranean Health Journal, 5, 241-246.

[62] AbuMadini, M.S., Rahim, S.I., Al-Zahrani, M.A. and Al-Johi, A.O. (2008) Two Decades of Treatment Seeking for Substance Use Disorders in Saudi Arabia: Trends and Patterns in a Rehabilitation Facility in Dammam. Drug and Alcohol Dependence, 97, 231-236. http://dx.doi.org/10.1016/j.drugalcdep.2008.03.034

[63] Hafeiz, H.B. (1995) Socio-Demographic Correlates and Pattern of Drug Abuse in Eastern Saudi Arabia. Drug and Alcohol Dependence, 38, 255-259. http://dx.doi.org/10.1016/0376-8716(95)90001-X

[64] Alhamad, A.M., Al-Sawaf, M.H., Osman, A.A. and Ibrahim, I.S. (2006) Differential Aspects of Consultaiton-Liaison Psychiatry in a Saudi Hospital. I: Referral Pattern and Clinical Indices. Eastern Mediterranean Health Journal, 12, 316-323.

[65] Alhamad, A.M., Al-Sawaf, M.H., Osman, A.A. and Ibrahim, I.S. (2006) Differential Aspects of Consultaiton-Liaison Psychiatry in a Saudi Hospital. II: Knowledge and Attitudes of Physicians and Patients. Eastern Mediterranean Health Journal, 12, 324-330.

[66] Alhuthail, Y.R. (2009) Timing of Referral to Consultation-Liaison Psychiatry. International Journal of Health Sciences, 3, 175-170.

[67] Qureshi, N.A., Al-Habeeb, T.A., Al-Ghamdy, Y.S., Magzoub, M.M.A., Schmidt, H.G. and van der Molen, H.T. (2001) Psychiatric Co-Morbidity in Primary Care and Hospitals Referrals, Saudi Arabia. Eastern Mediterranean Health Journal, 7, 492-501.

[68] Kishi, Y., Meller, W.H., Kato, M., Thurber, S., Swigart, S.E., Okuyama, T., Mikami, K., Kathol, R.G., Hosaka, T. and Aoki, T. (2007) A Comparison of Psychiatric Consultation-Liaison Services between Hospitals in the United States and Japan. Psychosomatics, 48, 517-522. http://dx.doi.org/10.1176/appi.psy.48.6.517

[69] Schellhorn, S.E., Barnhill, J.W., Raiteri, V., Faso, V.L. and Ferrando, S.J. (2009) A Comparison of Psychiatric Consultation between Geriatric and Non-Geriatric Medical Inpatients. International Journal of Geriatric Psychiatry, 24, 1054-1061. http://dx.doi.org/10.1002/gps.2221

[70] Mehmood, S.I., Kumar, A., Al-Binali, A. and Borleffs, J.C.C. (2012) Specialty Preferences: Trends and Perceptions among Saudi Undergraduate Medical Students. Medical Teacher, 34, S51-S60. http://dx.doi.org/10.3109/0142159X.2012.656753

[71] Compton, M.T., Frank, E., Elon, L. and Carrera, J. (2008) Changes in U.S. Medical Students' Specialty Interests over the Course of Medical School. Journal of General Internal Medicine, 23, 1095-1100. 
http://dx.doi.org/10.1007/s11606-008-0579-z

[72] El-Gilany, A.H., Amr, M. and Iqbal, R. (2010) Students’ Attitudes toward Psychiatry at Al-Hassa Medical College, Saudi Arabia. Academic Psychiatry, 34, 71-74. http://dx.doi.org/10.1176/appi.ap.34.1.71

[73] Amr, M. and Amin, T. (2012) Assessment Methods of an Undergraduate Psychiatry Course at Saudi University. Sultan Qaboos University Medical Sciences Journal, 12, 214-224.

[74] Gaffas, E.M., Sequeira, R.P., Al Namla, R.A. and Al-Harbi, K.S. (2012) Test Bluprints for Psychiatry Residency InTraining Written Examinations in Riyadh, Saudi Arabia. Advances in Medical Education and Practice, 3, 31-46.

[75] Afifi, M.M. (2005) Mental Health Publications from the Arab World Cited in PubMed, 1987-2002. Eastern Mediterranean Health Journal, 11, 319-328.

[76] Jaalouk, D., Okasha, A., Salamoun, M.M. and Karam, E.G. (2012) Mental Health Research in the Arab World. Social Psychiatry and Psychiatric Epidemiology, 47, 1727-1731. http://dx.doi.org/10.1007/s00127-012-0487-8

[77] Al-Harbi, K.S. (2012) Treatment-Resistant Depression: Therapeutic Trends, Challenges, and Future Directions. Patient Preference and Adherence, 6, 369-388. http://dx.doi.org/10.2147/PPA.S29716

[78] Al-Harbi, K.S. and Qureshi, N.A. (2012) Neuromodulation Therapies and Treatment-Resistant Depression. Medical Devices: Evidence and Research, 5, 53-65.

[79] Zaini, R.G., Abdulrahman, K.A.B., Al-Khotani, A.A., Al-Hayani, A.M.A., Al-Alwan, I.A. and Jastaniah, S.D. (2011) Saudi Meds: A Competence Specification for Saudi Medical Graduates. Medical Teacher, 33, 582-584. http://dx.doi.org/10.3109/0142159X.2011.578180

[80] National Plan for Science and Technologies, Detailed Themes, Medical and Health: Strategic Priorities for Advanced Medical and Health Research. http://www.kau.edu.sa/content.aspx?Site_ID=305\&lng=EN\&cid=65098

[81] Sambridge, A. (2010) Saudi Populations Stands at 27.1 Million; Expats Number 8.4 Million. http://www.arabianbusiness.com/saudi-population-stands-at-27-1m-expats-number-8-4m-340099.html

[82] Rahman, F. (1998) Health and Medicine in the Islamic Tradition. ABC International Group, Inc., Chicago.

[83] Dols, M.W. (2007) Insanity in Islamic Law. Journal of Muslim Mental Health, 2, 81-99. http://dx.doi.org/10.1080/15564900701238799

[84] Wahass, S. and Kent, G. (1997) A Comparison of Public Attitudes in Britain and Saudi Arabia towards Auditory Hallucinations. International Journal of Social Psychiatry, 43, 175-183. http://dx.doi.org/10.1177/002076409704300303

[85] Ratner, C. and El-Badwi, E. (2011) A Cultural Psychological Theory of Mental Illness, Supported by Research in Saudi Arabia. Journal of Social Distress and the Homeless, 20, 217-274. http://dx.doi.org/10.1179/105307811805472710 